\section{ScienceDirect}

Materials Today: Proceedings 00 (2018) 0000-0000 materialstoday:
PROCEEDINGS

www.materialstoday.com/proceedings

\title{
AEM 2018 \\ Determination of optimum welding parameters for the welding execution of steels used in underwater marine systems (including the submerged parts of Wave Energy Converters)
}

\author{
Alexandros G. Oikonomou ${ }^{\mathrm{a}}$, George A. Aggidis ${ }^{\mathrm{b}, *}$ \\ ${ }^{a} \mathrm{PhD}$ research Candidate, MSc in Welding Engineering, Metallurgical Engineer, Lancaster University Renewable Energy Group and Fluid \\ Machinery Group, Department of Engineering, Lancaster University, Lancaster, Bailrigg, Lancashire, LA1 4YR, United Kingdom \\ ${ }^{b}$ Professor, Lancaster University Renewable Energy Group and Fluid Machinery Group, Department of Engineering, Lancaster University, \\ Lancaster, Bailrigg, Lancashire, LA1 4YR, United Kingdom
}

\begin{abstract}
The experimental determination of the optimum values of welding parameters and consequently the optimum weld quality of shipbuilding and submarine steels which can be used in the future for the improvement of the quality of already existing underwater marine systems (including oil platforms, bridge columns and ships) and for the construction of new and unfamiliar underwater seastructures (including the submerged parts of Wave Energy Converters and Tidal Energy Converters) in many countries like Greece is an essential parameter from a technical, qualitative and economical point of view. The purpose of this study is the presentation, justification and discussion of the outputs of the welding experimental execution of three different steels (HY 100 steels, $316 \mathrm{Ti}$ and $\mathrm{S} 355 \mathrm{~J} 2+\mathrm{N}$ ) which are currently used in shipbuilding and submarine constructions.
\end{abstract}

(C) 2018 Elsevier Ltd. All rights reserved.

Selection and peer-review under responsibility of the scientific committee of the Third International Conference on Advanced Energy Materials.

Keywords: welding current; welding voltage; welding speed; HY 100 steel; heat input; FCAW; microscopic examination

\section{Introduction}

The weldability is an important mechanical property which affects the construction of various steel welded underwater marine systems [1]. The optimization of the arithmetic values of various welding parameters (such as

* Corresponding author. Tel.: +0-044-152-459-3052.

E-mail address: a.oikonomou@lancaster.ac.uk; g.aggidis@lancaster.ac.uk 
welding current, welding voltage, welding speed) provides the highest quality characteristics of the welded joint $[2,3]$. For this reason, the experimental determination of the optimum arithmetic values of welding parameters and consequently the optimum welding quality was executed with the three following steels which are currently used in shipbuilding and submarine constructions:

- HY 100 is an 100000 - psi high yield strength quenched and tempered fully killed and non-magnetizable steel with a good combination of strength and toughness which is used for submarine constructions and has many industrial applications in pressure vessels [4,5]. The basic advantages of the HY steel materials are their excellent resistance to underwater explosion shocks and their good weldability in heavy thicknesses with little preheat or no post weld heat treatment.

- The X6CrNiMo17-12-2 (316Ti) austenitic stainless steels are steels with titanium stabilization, the nominal chromium content higher than 16 percent and an excellent notch toughness at cryogenic temperatures [6]. The principal advantages of $316 \mathrm{Ti}$ steels are their higher corrosion and oxidation resistance than the standard grades of 316 , their better ductility and toughness than carbon and alloy steels and their good maintenance at elevated temperatures for a longer period without the presence of precipitation taking place [6,7].

- $\mathrm{S} 355 \mathrm{~J} 2+\mathrm{N}$ is a hot rolled normalized structural steel with a minimum yield strength of $355 \mathrm{~N} / \mathrm{mm}^{2}$ which has many common applications due to its excellent mechanical properties [8].

All welding experiments were robotically executed with the aid of Flux Cored Arc Welding (FCAW) process [9]. FCAW process is a semi - automatic or automatic arc welding process in which the heat required to melt and weld the material is produced by the establishment and maintenance of an electric arc between the tip of a continuously fed consumable filled with a flux and the work piece [3].

It is obvious from the relative references [9] that the welding parameters which mostly affect the quality characteristics of the welded joints and play a significant role during the FCAW process are the welding current, the welding voltage and the welding speed and for this reason they were selected as dominant during the experimental execution. The heat input, which is a relationship between the welding current, the welding voltage and the welding speed, is given from the following equation [3]:

$$
H I=\frac{V \cdot I \cdot 60}{1000 \cdot W S}
$$

\begin{tabular}{|ll}
\hline \multicolumn{2}{l}{ Nomenclature } \\
I & current (A) \\
V & voltage $(\mathrm{V})$ \\
WS & welding speed $(\mathrm{cm} / \mathrm{min})$ \\
HI & heat input $(\mathrm{KJ} / \mathrm{cm})$
\end{tabular}

\section{Experimental methodology}

Before of the beginning of the welding experimental execution, all steel plates were cleaned with the aid of shot blasting. FCAW operations were performed with the aid of a welding robot. Welding experimental execution between dissimilar steels was not investigated during this study.

The arithmetic values of the parameters such as thickness (i.e $15 \mathrm{~mm}$ ) and length (i.e $300 \mathrm{~mm}$ ) of each specimen, shielding gas, shielding gas flow rate, edge preparation (i.e single V-butt joint preparation with $60^{\circ}$ induced angle) of the welded joint, preheating temperature and interpass temperature were kept constant during the experimental execution, whereas the arithmetic values of the welding current, welding voltage and welding speed were changed. In each experiment all arithmetic values for each welding parameter and the number of welding layers for each welded specimen were recorded.

After the integration of the welding experimental execution the welded joints of the HY 100 steel specimens and 
the welded joints of the S355J2+N steel specimens were inspected with the aid of Visual Testing, Magnetic Particle Testing, Ultrasonic Testing and Radiographic Testing, whereas the welded joints of the 316Ti stainless steel specimens were inspected with the aid of Visual Testing, Liquid Penetrant Testing, Ultrasonic Testing and Radiographic Testing [10]. All welded defects which are described in Table 1 were recorded and the specifications [11] which describe the acceptance and unacceptance criteria of the welding defects for fusion welded joints were implemented.

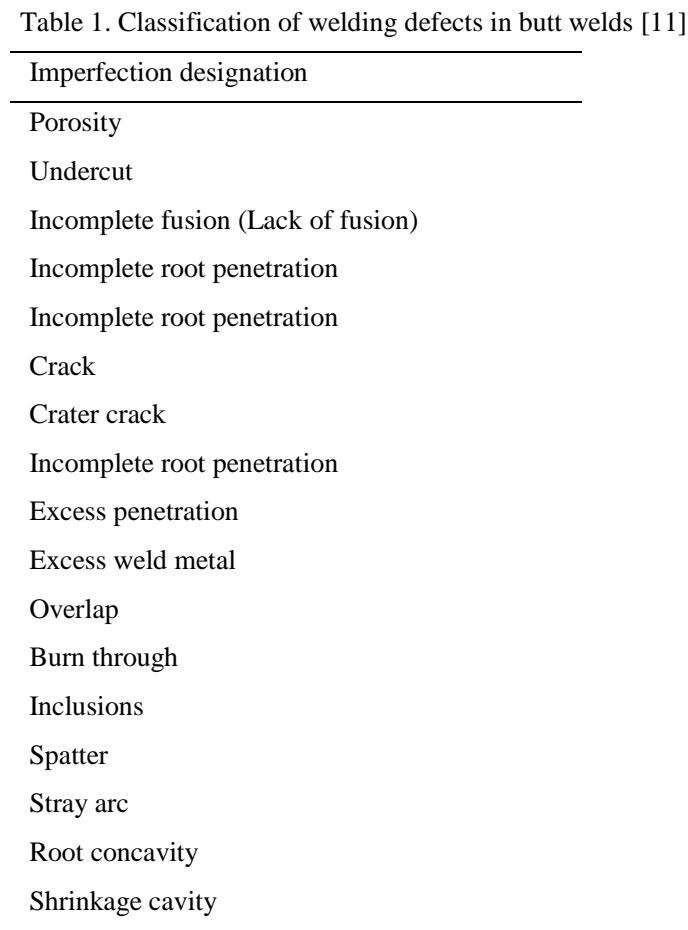

After the integration of the non-destructive evaluation of the welded steel specimens, the preparation of the metallographic specimens was conducted in accordance with the specification ASTM E3 [12]. The welded specimens were mechanically cut perpendicular to the welding direction with the aid of a saw, grinded and polished through a series of metallographic papers until the desirable surface finish has been accomplished. The primary objective of metallographic examinations of the welded specimens is the revelation of the metallurgical structure in the parent metal, in the filler metal and in the heat affected zone in accordance with the iron-iron carbide phase diagram with the aid of a light optical or scanning electron microscope [2,12]. Macroscopic examination was used to determine the number of welding layers whereas microscopic examination was used to determine excessively small imperfections at magnification of about 50 times or higher [2]. The welded specimens were etched with the suitable etchant in accordance with the specification ASTM E407 [13] such that the regions of the parent metal, filler metal and HAZ were revealed.

\section{Results and discussion}

The presentation and the discussion of the results which came out from the welding experimental execution, the macroscopic and the microscopic examination of the steels specimens welded with the optimum welding parameters is included in this chapter: 


\subsection{Optimum weldability of each welded steel specimen}

The optimum arithmetic values of the HY 100 steel welded joints are presented in table 2:

Table 2. Optimum weldability of HY 100 welded steel specimens

\begin{tabular}{llllll}
\hline Welding layer & Current $(I)$ & Voltage $(V)$ & $\begin{array}{l}\text { Welding speed } \\
(\mathrm{cm} / \mathrm{min})\end{array}$ & $\begin{array}{l}\text { Heat input } \\
(\mathrm{KJ} / \mathrm{cm})\end{array}$ & $\begin{array}{l}\text { Presence of } \\
\text { welding defects }\end{array}$ \\
\hline 1 & 186 & 26.2 & 15 & 19.49 & no defects \\
2 & 230 & 25.9 & 28 & 12.77 & no defects \\
3 & 232 & 23.7 & 35 & 9.43 & no defects \\
4 & 232 & 23.3 & 33 & 9.82 & no defects \\
5 & 230 & 23.2 & 35 & 9.14 & no defects \\
6 & 230 & 23.2 & 34 & 9.14 & no defects \\
7 & 230 & 25.2 & & 10.22 & no defects \\
\hline
\end{tabular}

The optimum arithmetic values of the 316Ti steel welded joints are presented in table 3 :

Table 3. Optimum weldability of 316Ti welded steel specimens

\begin{tabular}{llllll}
\hline Welding layer & Current $(I)$ & Voltage $(V)$ & $\begin{array}{l}\text { Welding speed } \\
(\mathrm{cm} / \mathrm{min})\end{array}$ & $\begin{array}{l}\text { Heat input } \\
(\mathrm{KJ} / \mathrm{cm})\end{array}$ & $\begin{array}{l}\text { Presence of } \\
\text { welding defects }\end{array}$ \\
\hline 1 & 190 & 27.3 & 19 & 16.38 & no defects \\
2 & 190 & 26 & 38 & 7.8 & no defects \\
3 & 190 & 26 & 38 & 7.8 & no defects \\
4 & 190 & 26 & 38 & 7.8 & no defects \\
5 & 190 & 26 & 38 & 7.8 & no defects \\
6 & 190 & 26 & 38 & 7.8 & no defects \\
7 & 190 & 26 & 38 & 7.8 & no defects \\
8 & 190 & 26 & 38 & 7.8 & no defects \\
9 & 190 & 26 & 38 & 7.8 & no defects \\
\hline
\end{tabular}

The optimum arithmetic values of the $\mathrm{S} 355 \mathrm{~J} 2+\mathrm{N}$ steel welded joints are presented in table 4:

Table 4. Optimum weldability of S355J2+N welded steel specimens

\begin{tabular}{llllll}
\hline Welding layer & Current $(I)$ & Voltage $(V)$ & $\begin{array}{l}\text { Welding speed } \\
(\mathrm{cm} / \mathrm{min})\end{array}$ & $\begin{array}{l}\text { Heat input } \\
(\mathrm{KJ} / \mathrm{cm})\end{array}$ & $\begin{array}{l}\text { Presence of } \\
\text { welding defects }\end{array}$ \\
\hline 1 & 195 & 25.9 & 17 & 17.38 & no defects \\
2 & 230 & 28.6 & 38 & 10.38 & no defects \\
3 & 230 & 26 & 32 & 11.21 & no defects \\
4 & 230 & 26 & 32 & 11.21 & no defects \\
5 & 230 & 26.8 & 35 & 10.56 & no defects \\
6 & 230 & 27 & 34 & 10.64 & no defects \\
7 & 232 & 26.9 & 11.01 & no defects \\
\hline
\end{tabular}

After the integration of sufficient welding experiments with three different steels, it is obvious from the tables 2,3 and 4 that there is a direct relationship between the heat input and the number of the welding defects. The lower the 
heat input is applied during the welding execution, the lower the likelihood of appearance of welded defects. In HY 100 steel welded specimens and in $\mathrm{S} 355 \mathrm{~J} 2+\mathrm{N}$ steel welded specimens each welding layer must have different values of parameters such that the optimum weld quality is provided. Also it is worth mentioning that the values of the welding parameters which were applied in the welding layer 1 (or root layer) differ from the values of the welding parameters which were applied in the subsequent welding layers because it is desirable in the root layer to achieve high penetration and uniform weld bead by using lower values of welding speed and not so high values of current and voltage in order to maintain the heat input constant. The values of the welding current in the welding layers of HY 100 and S355J2+N steel welded specimens are higher than the relative values of the 316Ti steel welded specimens.

\subsection{Macroscopic examination of the steel welded specimens with the optimum weldability}

The macroscopic examination illustrated the distinguished regions of the welding layers and the regions of the HAZ, the parent metal and the filler metal of the steels under examination (see Fig.1,2,3). A scrutinized examination of each macro photograph identified some shadow regions with different darkness or brightness in the HAZ regions of the parent metal and these regions were created due to the complicated influence between each subsequent welding layer and the previous one.

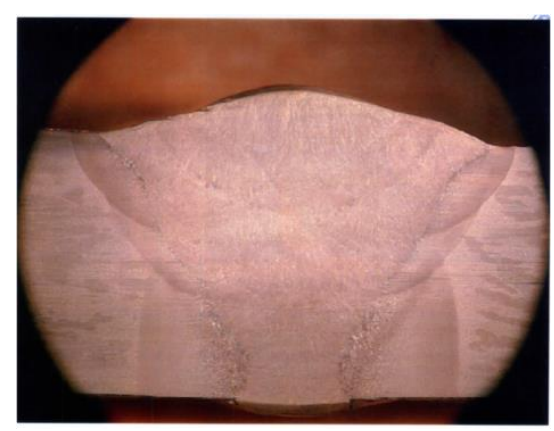

Fig. 1. Macroscopic examination of HY 100 welded steel specimen

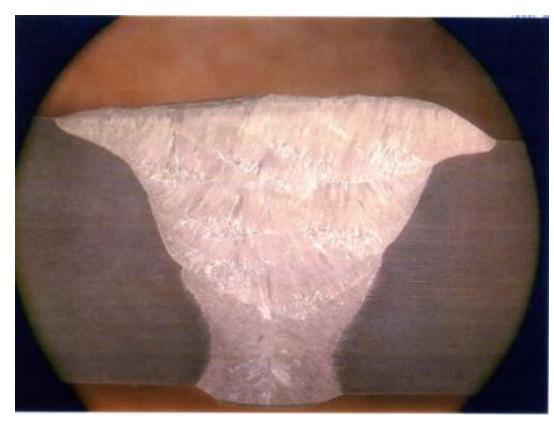

Fig. 2. Macroscopic examination of $316 \mathrm{Ti}$ welded steel specimen.

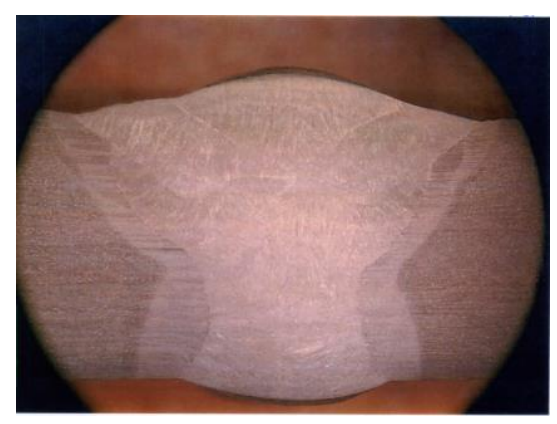


Fig. 3. Macroscopic examination of $\mathrm{S} 355 \mathrm{~J} 2+\mathrm{N}$ welded steel specimen.

\subsection{Microscopic examination of the steel welded specimens with the optimum weldability}

The microscopic examination illustrated the distinguished phases and the regions of the HAZ, the parent metal and the filler metal of the steels under examination (see Fig.4,5,6). The phases which were microscopically observed in the heat affected zone of the parent metal depend on the cooling rate of the austenite which is familiar from the iron - iron carbide phase diagram [14].

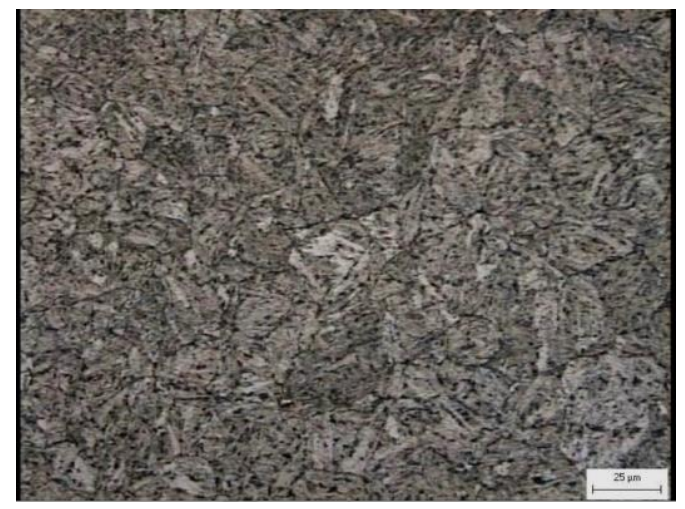

Fig. 4. Bainitic phase in the HAZ region of HY 100 welded steel specimen

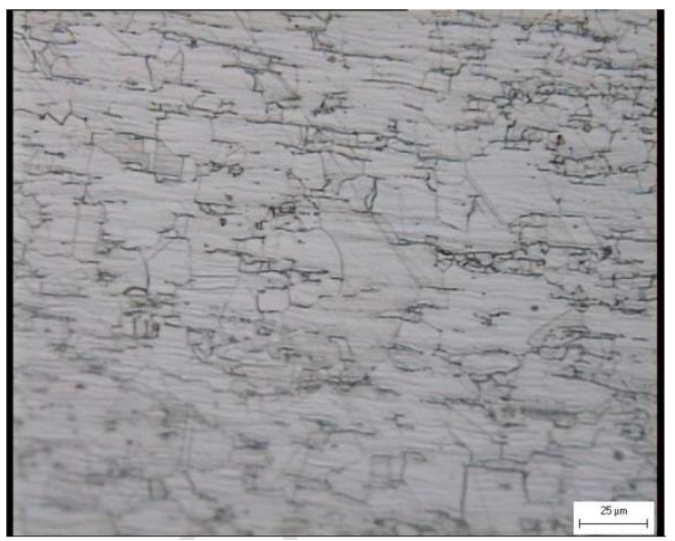

Fig. 5. Austenitic and delta ferritic phase in the HAZ region of 316Ti welded steel specimen

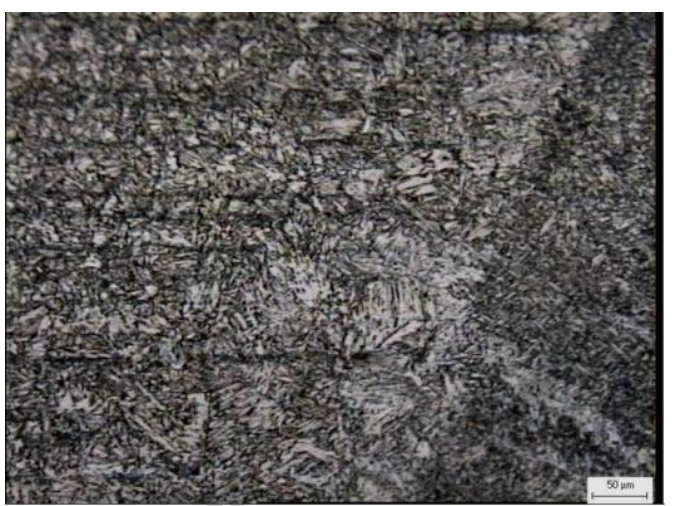


Fig. 6. Bainitic phase in the HAZ region of HY 100 welded steel specimen

\section{Conclusions}

Welding current, welding voltage and welding speed are the most important welding parameters which influence the quality of the HY 100 steel welded joints, the 316Ti steel welded joints and the S355J2+N steel welded joints. The heat input in each welding layer must have low values such that qualitative welded joints are accomplished. Macroscopic examination did not illustrate any lack of sidewall fusion or another defect in the three welded joints under examination. The results of the welding experimental execution and of the metallographic examination can be the basis for the preparation of the final Welding Procedure Specification for each steel.

\section{Acknowledgements}

The authors would like to thank Mr. Alexandros John Oikonomou (Industry Technical Engineer, grandfather of the $\mathrm{PhD}$ research Candidate Mr. Alexandros George Oikonomou) for his support, technical guidance and advise.

\section{References}

[1] B. Le Mehaute, Daniel M. Hanes, Ocean Engineering Science, Volume 9, John Wiley \& Sons, USA, 1990

[2] American Welding Society, Welding Inspection Handbook, third ed., Miami, USA, 1987

[3] American Welding Society, Welding Handbook, Volume 2, eighth ed., Miami, USA, 1991

[4] R. W. Flax, R. E. Keith and M.D. Randall, Welding the HY Steels, American Society for Testing and Materials, New York, 1971

[5] Ulrich Gabler, Submarine Design, Bernand \& Graefe Verlag, Bonn, Germany,2000

[6] American Welding Society, Welding Handbook, Volume 4, forth ed., Miami, USA, 1998

[7] J. Brnic , G. Turkalj, M. Canadija, D. Lanc, AISI 316Ti (1.4571) steel-Mechanical, creep and fracture properties versus temperature, Journal of Constructional Steel Research, Elsevier, 2011, pp. 1948-1952

[8] R. M. Plum, Fatigue crack detection on structural steel members by using ultrasound excited thermography, KIT Scientific Publishing, 2015

[9] S.A. Mohamat, I.A. Ibrahim, A. Amir, A. Ghalib, The effect of flux core arc welding (FCAW) processes on different parameters, Procedia Engineering 41, Elsevier, 2012, pp. 1497-1501.

[10] R. Halmsam, Introduction to the Non-Destructive Testing of Welded Joints, second ed., Abington Publishing, Cambridge, England, 1996.

[11]ISO 5817:2014, Welding -- Fusion-welded joints in steel, nickel, titanium and their alloys (beam welding excluded) -- Quality levels for imperfections , available at https://www.iso.org/standard/54952.html (accessed 2nd June 2018)

[12]ASTM E3-11:2017, Standard Guide for Preparation of Metallographic Specimens, available at https://www.astm.org/Standards/E3.htm (assessed 2nd June 2018)

[13] ASTM E340:2015, Standard Practice for Macroetching Metals and Alloys, available at https://www.astm.org/Standards/E340.htm (assessed 2nd June 2018)

[14] W. D. Callister, Jr., D. G. Rethwisch, Fundamentals of Materials Science and Engineering, forth ed., John Wiley \& Sons, USA, 2013 